\title{
Effect of The Use of Different Whey Proteins on Some Properties of Sahlep Beverage Prepared from Functional Sahlep Powder ${ }^{\#}$
}

\author{
Kurban Yaşar*, Adnan Bozdoğan
}

Food Engineering, Engineering Faculty, Osmaniye Korkut Ata University, 80000 Karacaoğlan Kambus/Osmaniye, Turkey

\section{A R T I C LE IN F O}

\#This work was presented to the conference (III. International Conference on

Engineering and Natural Science) held on 3-7 May 2017

\section{Research Article}

Received 26 August 2017

Accepted 16 March 2018

\section{Keywords}

Sahlep

Sahlep powder

Whey protein

Viscosity

Sensory analysis

*Corresponding Author:

E-mail: kurbanyasar@osmaniye.edu.tr \begin{abstract}
A B S T R A C T
Sahlep powder is obtained by drying and grinding after the plant tubers of the Orchidaceae family removed from the soil. Sahlep powder, which is unique to Turkey, is used in Maras ice cream, sahlep beverage and medicine production. There is a growing interest in healthy nutrition in the world. This increasing is increased the demand for functional food. Whey proteins are increasingly used in foods in recent years due to the functional compounds they contain. In this study, it was tried to increase the functional properties of sahlep using Whey proteins. For this purpose, different Sahlep powder was prepared by using Whey protein concentrate (WPC 35\%), demineralized whey protein powder, milk powder, sahlep, sugar, starch, cinnamon and ginger. The different Sahlep produced were made into sahlep beverage with water and $\mathrm{pH}$, viscosity and sensory analysis were made. As a result of the analyzes made, the use of Whey proteins statistically affected the viscosity value of the sahlep beverage. It was determined that the use of different whey proteins affected the color, taste and smell values of Sahlep. As a result of the sensory evaluation performed by the panelists, sahlep beverage produced in $25 \%$ whey protein concentrate (WPC $35 \%$ ) $+75 \%$ milk powder mixture was preferred. It is may be suggested to produce sahlep powder and sahlep beverage by using $25 \%$ whey protein concentrate (WPC $35 \%)+75 \%$ milk powder mixture.
\end{abstract}

DOI: https://doi.org/10.24925/turjaf.v6i5.520-523.1590

\section{Introduction}

Sahlep is a powder obtained from plant tubers of the Orchid family (Orchidaceae). The tubers that are removed from the soil are first dried and then grinded to obtain sahlep powder. Sahlep contains too much glucomannan. Glucomannan chemical structure is formed by linear chains composed of glucose and mannose linked by $\beta$ - $(1 \rightarrow 4)$ glycosidic bonds. Sahlep powder is used in Maraş ice cream, which is unique to Turkey, milk Sahlep beverage and medicine production (Kurt and Kahyaoglu, 2017).

Functional properties of Sahlep depend on its composition, in particular the content of glucomannan (Bozdoğan and Yaşar, 2016). Glucomannan is a watersoluble neutral fiber and have positive health-promoting effects (Yaşar et al., 2009). It is a compound that helps to reduce blood sugar abnormalities such as hypoglycemia, to treat chronic diseases and to lose weight (Farhoosh and Riazi, 2007). Glucomannan is a stabilizer with high water holding capacity. In addition, it has significant effect on the formation of homogenous structure, stiffness and aroma of Maraş ice cream (Bozdoğan and Yaşar, 2016).
Tekinşen and Güler (2010) collected and dried ten of the Orchidaceae species grown in the Eastern Mediterranean region of Turkey (Dactylorhiza osmanica var. osmanica, Ophrys mammosa, Orchis anatolica, Orchis coriophora, Orchis italica, Orchis morio, Orchis palustris, Orchis simia, Orchis tridentata and Serapias vomeracea ssp. orientalis), then grinded to obtain Sahlep powder. Finally they determined that the amount of glucomannan in Sahlep powder varied between 17.1$56.6 \%$. Also, Farhoosh and Riazi (2007) found that the glucomannan content in Iran Sahlep varied between 17.1$56.6 \%$.

Approximately $80 \%$ of the proteins found in the milk are casein and $20 \%$ are whey proteins. Whey proteins are composed of $\beta$-lactoglobulin (50\%), $\alpha$-lactalbumin (20\%), serum albumin (10\%), immunoglobulin (10\%) and proteose-peptone $(10 \%)$ and other minor protein fractions (lactoferrin etc.) (Gür et al. 2010).

Whey protein is known as a protein of high quality due to the amino acids it contains. Due to the nutritional and functional properties of whey proteins, the consumption of commercial whey protein products such 
as whey protein concentrates (WPC) and whey protein isolates (TEFE) has been increasing. Whey protein additives are widely used in whey protein-fortified sports beverages, and medical and clinical nutritional beverages (Sutariya and Patel, 2017).

Whey proteins are known to have important effects on human health. These include: allergic inhibition by $\beta$ lactoglobulin, protection against infection by $\alpha$ lactalbumin, colitis inhibition by glycromacropeptide, immunity to prevent cancer and inflammatory disease inhibition by lactoferrin. Whey proteins inhibit the angiotensin-I converting enzyme (ACE) and help control hypertension. Whey proteins are commercially marketed for promoting cancer treatment, fighting inflammatory diseases, healing wounds, promoting bone repair, reducing blood pressure and cholesterol, and acne treatment (Krissansen, 2007).

Whey proteins are known to have functional properties such as content thickener, gel formation enhancement, emulsion formation, water retention and inhibition of serum separation. In this respect, whey proteins are used in many food products to improve sensory and textural qualities and enhance endurance. Functional properties of milk proteins are also defined by characteristics other than nutrition such as structure, appearance, texture and viscosity (Özcan and Delikanlı, 2011).

The aim of this research is to obtain high-protein Sahlep beverage using nutritious whey proteins.

\section{Materials and Method}

\section{Materials}

The materials are as follows: Milk (from Osmaniye private milk factory), demineralized whey powder, whey protein concentrate (WPC 35) and milk powder (from Enka Milk, Konya, Turkey), starch (from Corn starch, Dr. Oetker, Izmir, Turkey), Sahlep (from a private company in Kahramanmaras, Turkey), sugar (from Torku Sugar, Konya, Turkey), ginger and cinnamon (from Bağdad Spices, Kahramanmaras, Turkey).

\section{Method}

\section{Sahlep Beverage Production}

In this study, powder mixtures at different ratios were obtained by using whey proteins (whey protein concentrate WPC \%35 and demineralized whey protein powder) and milk powder, then Sahlep beverage was prepared using this powder mixtures by mixing with water, sugar, starch, cinnamon, and ginger. As a control sample, another Sahlep beverage without whey proteins was produced by mixing cow milk, Sahlep, sugar, starch, cinnamon and ginger in the amounts indicated in Table 1, and the mixture was homogenized with a homogenizer (Ultra Turrax, Janke \& Kuntel KG, IKA, Werk, Germany). The mixture was heated at $90^{\circ} \mathrm{C}$ for 15 minutes, and then cooled down to $25^{\circ} \mathrm{C}$ and stored at $+5^{\circ} \mathrm{C}$ for the analyses. Sahlep beverage production process is showed in Figure 1.

\section{Sahlep Beverage Analyses}

pH analysis: $\mathrm{pH}$ was determined by using Orion StarTM A $211 \mathrm{pH}$ Benchtop Meter digital $\mathrm{pH}$ meter (Thermo Scientific, Waltham, MA).

Viscosity analysis: The viscosity was measured at $40^{\circ} \mathrm{C}$ by Selecta STS-2011 Viscometer (Barcelona, Spain).

Sensory analysis: was performed by 12 trained panelists from Osmaniye Korkut Ata University, Engineering Faculty, Food Engineering Department. The 9-point hedonic scale (1-9 points) was used in sensory analysis (Meilgaard et al., 1999).

\section{Statistical Analysis}

One way analysis of variance was applied to obtain chemical and sensory results. The Duncan multiple comparison test was carried out to assess the differences between the groups (Düzgüneş et al., 1987).

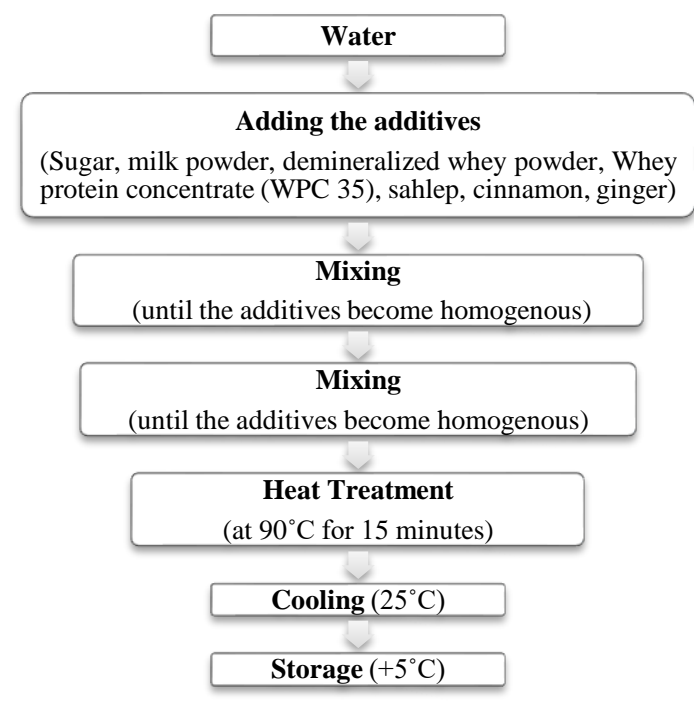

Figure 1 Sahlep beverage production

Table 1 The additives used in Sahlep beverage production and their usage ratios

\begin{tabular}{|c|c|c|c|c|c|c|c|c|c|c|}
\hline Samples & $\mathrm{W}$ & $\mathrm{M}$ & DWP & WPC & MP & ST & $\mathrm{G}$ & $\mathrm{C}$ & $\mathrm{SH}$ & SG \\
\hline Control & - & 1000 & - & - & - & 3 & 0.25 & 0.25 & 10 & 100 \\
\hline $\begin{array}{l}\text { Sample } 1(25 \% \text { whey protein concentrate (WPC } \\
\% 35)+75 \% \text { milk powder })\end{array}$ & 1000 & - & - & 25 & 75 & 3 & 0.25 & 0.25 & 10 & 100 \\
\hline $\begin{array}{l}\text { Sample } 2(50 \% \text { whey protein concentrate (WPC } \\
\% 35)+50 \% \text { milk powder })\end{array}$ & 1000 & - & - & 50 & 50 & 3 & 0.25 & 0.25 & 10 & 100 \\
\hline $\begin{array}{l}\text { Sample } 3(25 \% \text { Demineralized whey powder }+ \\
75 \% \text { milk powder })\end{array}$ & 1000 & - & 25 & - & 75 & 3 & 0.25 & 0.25 & 10 & 100 \\
\hline $\begin{array}{l}\text { Sample } 4 \text { ( } 50 \% \text { Demineralized whey powder }+ \\
50 \% \text { milk powder) }\end{array}$ & 1000 & - & 50 & - & 50 & 3 & 0.25 & 0.25 & 10 & 100 \\
\hline
\end{tabular}

W: Water (mL), M: Milk (mL), DWP: Demineralized whey powder (g), WPC: Whey protein concentrate (WPC 35)(g), MP: Milk powder (g), ST: Starch (g), G: Ginger (g), C: Cinnamon (g), SH: Sahlep (g), SG: Sugar (g) 


\section{Results and Discussion}

The $\mathrm{pH}$ and viscosity values of the Sahlep beverages are presented in Table 2. As seen in Table 2, the samples did not have a statistically significant difference in terms of $\mathrm{pH}$ values $(\mathrm{P}>0.05)$. Yaşar et al. (2009) reported a variation of the $\mathrm{pH}$ values between 6.49 and 6.62 in a study investigating the rheological properties of Sahlep prepared using glucomannan and galactomannan. On the other hand, the difference between samples in terms of viscosity value was found to be statistically significant $(\mathrm{P}<0.05)$. The viscosity has increased with the increase of whey protein concentrate. The lowest viscosity value was found in the control sample. The highest viscosity value was found in the sample 2. Bozdoğan and Yaşar (2016) reported a variation of the viscosity values between 105.50 and 165.72 in a study conducted to increase the nutritional value of Sahlep beverage.

Color, structure, scent, taste and overall sensory assessment results of the Sahlep beverage are presented in Table 3. A statistically significant difference was found between the samples in terms of color $(\mathrm{P}<0.05)$. The highest color value was found in the control sample, whereas sample 1 had second highest value. The difference between Samples 3, Sample 2 and Sample 4 was insignificant $(\mathrm{P}>0.05)$. However, the difference between the control sample, Sample 1 and the others was significant $(\mathrm{P}<0.05)$. In terms of structure variable, the control sample had the highest scores, and Sample 1 had second highest scores. The difference between those samples was significant $(\mathrm{P}<0.05)$.

A statistically significant difference was found between the samples in terms of scent and taste $(\mathrm{P}<0.05)$. The highest these values were found in the control sample, whereas sample 1 had second highest value. On the other hand, no statistically significant difference was found between Sample 2, Sample 3 and Sample 4.

According to the general assessment result, a statistically significant difference was found between the samples $(\mathrm{P}<0.05)$. The control sample had the highest scores, whereas Sample 1 had second highest scores, and the difference between these samples was statistically significant $(\mathrm{P}<0.05)$. Alpaslan and Hayta (2007) examined the sensory and rheological properties of Sahlep prepared by adding soymilk at different ratios $(0 \%, 25 \%, 50 \%$ and $75 \% \mathrm{~g} / 100 \mathrm{~g}$ milk) to cow milk. The sample with $25 \%$ soy milk had the highest score in terms of sensory characteristics. Telcioglu and Kayaciger (2007) examined the effect of sweeteners (Aspartame, Saccharine and Cyclamate) on the sensory and rheological properties of Sahlep. The researchers have reported that Saccharine improved rheological properties of Sahlep and also received high scores in sensory analysis.

Table $2 \mathrm{pH}$ and viscosity values of Sahlep beverages

\begin{tabular}{l|cc}
\hline \multicolumn{1}{c|}{ Samples } & $\mathrm{pH}$ & Viscosity (cP) \\
\hline Control & $6.48^{\mathrm{a}} \pm 0.24$ & $110.5^{\mathrm{d}} \pm 12$ \\
Sample 1 (25\% whey protein concentrate (WPC \%35) $+75 \%$ milk powder) & $6.53^{\mathrm{a}} \pm 0.21$ & $252.5^{\mathrm{bc}} \pm 67$ \\
Sample 2 (50\% whey protein concentrate (WPC \%35) +50\% milk powder) & $6.55^{\mathrm{a}} \pm 0.38$ & $380.0^{\mathrm{a}} \pm 28$ \\
Sample 3 (25\% Demineralized whey powder + 75\% milk powder) & $6.68^{\mathrm{a}} \pm 0.14$ & $267.0^{\mathrm{b}} \pm 14$ \\
Sample 4 (50\% Demineralized whey powder + 50\% milk powder) & $6.46^{\mathrm{a}} \pm 0.09$ & $170.0^{\text {cd }} \pm 14$ \\
\hline
\end{tabular}

Different letters in the same column indicate statistically significant differences $(\mathrm{P}<0.05)$.

Table 3 Sensory assessment results of Sahlep beverages

\begin{tabular}{l|ccccc}
\hline \multicolumn{1}{c|}{ Samples } & Color & Structure & Scent & Taste & Overall \\
\hline Control & $7.92^{\mathrm{a}} \pm 1.26$ & $7.23^{\mathrm{a}} \pm 1.28$ & $7.15^{\mathrm{a}} \pm 1.31$ & $7.04^{\mathrm{a}} \pm 1.28$ & $7.36^{\mathrm{a}} \pm 1.41$ \\
Sample 1 & $7.57^{\mathrm{a}} \pm 1.10$ & $6.77^{\mathrm{b}} \pm 1.46$ & $6.35^{\mathrm{ab}} \pm 1.41$ & $6.27^{\mathrm{ab}} \pm 1.46$ & $6.81^{\mathrm{b}} \pm 1.29$ \\
Sample 2 & $7.27^{\mathrm{b}} \pm 1.16$ & $6.54^{\mathrm{c}} \pm 1.48$ & $6.00^{\mathrm{b}} \pm 1.62$ & $5.58^{\mathrm{b}} \pm 1.63$ & $6.38^{\mathrm{c}} \pm 1.70$ \\
Sample 4 & $7.30^{\mathrm{b}} \pm 1.56$ & $6.55^{\mathrm{c}} \pm 1.48$ & $6.31 \mathrm{a}^{\mathrm{b}} \pm 1.56$ & $6.04^{\mathrm{b}} \pm 1.79$ & $6.50^{\mathrm{c}} \pm 1.86$ \\
Sample 4 & $6.85^{\mathrm{b}} \pm 1.68$ & $6.54^{\mathrm{c}} \pm 1.84$ & $5.73^{\mathrm{b}} \pm 1.66$ & $6.11^{\mathrm{b}} \pm 1.70$ & $6.23^{\mathrm{c}} \pm 1.72$ \\
\hline
\end{tabular}

Different letters in the same column indicate statistically significant differences $(\mathrm{P}<0.05)$.

\section{Conclusions}

Considering the results of the analysis made with the control Sahlep sample and the samples prepared with whey proteins (whey protein concentrate WPC \%35 and demineralized whey protein powder) and milk powder additives, it was determined that following the control example, Sample 1 (25\% whey protein concentrate (WPC $\% 35)+75 \%$ milk powder) received the highest score in terms of color, scent, structure, taste and overall assessment. Therefore, Sample 1 was the closest to the control sample. It can be suggested that it is possible to increase nutritional value of Sahlep by adding $25 \%$ whey protein concentrate (WPC \%35) and $75 \%$ milk powder additive.

\section{References}

Alpaslan M, Hayta M. 2007. "Effect of Soymilk Substitution on the Rheological and Sensory Properties of Sahlep (Traditional Turkish Milk Beverage).” International Journal of Food Properties 10: 413-420. DOI:10.1080/ 10942910600813596.

Bozdoğan A, Yaşar K. 2016. "Increasing The Nutritional Value of Sahlep.” Journal of Food Physics 28-29:33-39.

Düzgüneş O, Kesici T, Kavuncu O, Gürbüz F. 1987. Araştırma ve Deneme Metotlarl, (Ístatistik Metotlart-II). Ankara Üniversitesi Ziraat Fakültesi Yayınları No: 1021, Ankara, Türkiye.

Farhoosh R, Riazi A. 2007. “A Compositional Study on Two Current Types of Sahlep in Iran and Their Rheological Properties as a Function of Concentration and Temperature." Food Hydrocolloids 21(4): 261-265. DOI:10.1016/ j.foodhyd.2006.07.021 
Gür F, Güzel M, Öncül N, Yıldırım, Z., Yıldırım, M. 2010. "Biological and Physiological Activities of Whey Proteins and Their Derivatives." Akademik Gida 8 (1). 23-31.

Krissansen GW. 2007. "Emerging Health Properties of Whey Proteins and Their Clinical Implications." Journal of the American College of Nutrition 26 (6), 713-723. DOI:10.1080/07315724.2007.10719652.

Kurt A, Kahyaoglu T. 2017. "Purification of Glucomannan from Sahlep: Part 1. Detailed Rheological Characteristics." Carbohydrate Polymers 168: 138-146. DOI: 10.1016/j.carbpol.2017.03.060.

Meilgaard M, Civille GV, Carr BT. 1999. Sensory Evaluation Techniques (3rd ed.). CRC Press, Boca Raton, Florida, USA.

Özcan T, Delikanlı B. 2011. "The Functional Effects Of Whey Protein Additives For Improvement Of Textural Properties Of Foods." Journal of Agricultural Faculty of Uludag University 2011, Cilt 25 (2):77-88.
Sutariya S, Patel H. 2017. "Effect of Hydrogen Peroxide on Improving the Heat Stability of Whey Protein Isolate Solutions." Food Chemistry 223.114-120. DOI: 10.1016/j. foodchem.2016.12.013.

Tekinşen KK, Güner A. 2010. "Chemical Composition and Physicochemical Properties of Tubera Sahlep Produced from Some Orchidaceae Species." Food Chemistry 121: 468-471. DOI:10.1016/j.foodchem.2009.12.066.

Telcioglu A, Kayacier A. 2007. " The Effect of Sweeteners and Milk Type on the Rheological Properties of Reduced Calorie Sahlep Beverage." African Journal of Biotechnology 6 (4), 465-469.

Yaşar K, Kahyaoğlu T, Şahan N. 2009. "Dynamic Rheological Characterization of Sahlep Glucomannan/GalactomannanBased Milk Beverages." Food Hyrdocolloids, 23: 13051311. DOI: 10.1016/j. foodhyd.2008.11.005. 